\title{
Electrochemical Deposition of CdTe Semiconductor Thin Films for Solar Cell Application Using Two-Electrode and Three-Electrode Configurations: A Comparative Study
}

\author{
O. K. Echendu, ${ }^{1,2}$ K. B. Okeoma, ${ }^{2}$ C. I. Oriaku, ${ }^{3}$ and I. M. Dharmadasa ${ }^{1}$ \\ ${ }^{1}$ Electronic Materials and Sensors Group, Materials and Engineering Research Institute, Sheffeld Hallam University, \\ Sheffield S1 1WB, UK \\ ${ }^{2}$ Thin Film Research Group, Department of Physics, Federal University of Technology, PMB 1526, Owerri, Nigeria \\ ${ }^{3}$ Engineering Physics Group, Department of Physics, Michael Okpara University of Agriculture, Umudike, PMB 7267, \\ Umuahia, Nigeria \\ Correspondence should be addressed to O. K. Echendu; oechendu@yahoo.com
}

Received 28 January 2016; Revised 27 May 2016; Accepted 29 May 2016

Academic Editor: Patrice Berthod

Copyright @ 2016 O. K. Echendu et al. This is an open access article distributed under the Creative Commons Attribution License, which permits unrestricted use, distribution, and reproduction in any medium, provided the original work is properly cited.

\begin{abstract}
Thin films of CdTe semiconductor were electrochemically deposited using two-electrode and three-electrode configurations in potentiostatic mode for comparison. Cadmium sulphate and tellurium dioxide were used as cadmium and tellurium sources, respectively. The layers obtained using both configurations exhibit similar structural, optical, and electrical properties with no specific dependence on any particular electrode configuration used. These results indicate that electrochemical deposition (electrodeposition) of CdTe and semiconductors in general can equally be carried out using two-electrode system as well as the conventional three-electrode system without compromising the essential qualities of the materials produced. The results also highlight the advantages of the two-electrode configuration in process simplification, cost reduction, and removal of a possible impurity source in the growth system, especially as the reference electrode ages.
\end{abstract}

\section{Introduction}

The electrochemical deposition (or simply electrodeposition) of CdTe for the fabrication of CdS/CdTe solar cells has received research attention for quite some time now [16]. The manufacturability and scalability of this simple but powerful process have been undoubtedly demonstrated by British Petroleum (BP Solar) company in the late 1990s by the production of solar panels of $\sim 1 \mathrm{~m}^{2}$ with over $10 \%$ conversion efficiency [4]. The conventional electrodeposition setup involves the use of three-electrode system (working electrode (the cathode), counter electrode (the anode), and the reference electrode) and most of the work done so far on electrodeposition of semiconductors in general has been on the basis of the three-electrode system [1-7]. It is well known that, in the three-electrode system, the potential of the working electrode is measured relative to the reference electrode which itself has a well-known and stable electrode potential. As a result the potential on the working electrode is precisely controlled. This has the advantage of producing materials with controlled stoichiometry since the effects of changes in certain deposition parameters such as stirring are minimised. In the two-electrode system, on the other hand, it is also known that the potential of the working electrode is measured relative to the counter electrode and the potential of the working electrode is not finely controlled as in the three-electrode system. The use of simple two-electrode configuration for electrodeposition of semiconductors is uncommon. As a result, only very few reports can be found in the literature involving the use of two-electrode system for the electrodeposition of compound semiconductors for solar cell fabrication [8-12].

In the electrodeposition of CdTe thin films in particular, reports on the use of two-electrode configuration are very scarce and the few available publications come principally from the authors' research group [8, 10-14]. This situation 
therefore prompted the use of two-electrode configuration alongside the conventional three-electrode configuration in the present work to study the possible effects of these different electrode configurations on the quality of CdTe layers produced as it regards their application in solar cell production. In addition, in the authors' research group, the suspicion that possible leakage of unwanted groups $1 \mathrm{~A}$ and $1 \mathrm{~B}$ ions like $\mathrm{K}^{+}$and $\mathrm{Ag}^{+}$from saturated calomel electrode (SCE) and $\mathrm{Ag} / \mathrm{AgCl}$ reference electrodes could lead to the deterioration of the efficiency of CdTe solar cells as the reference electrode ages gave impetus to the investigation of the use of the twoelectrode system in the electrodeposition of CdTe and indeed other semiconductors. These ions are known to have severe detrimental effects on CdTe-based solar cells $[6,15]$. The twoelectrode approach therefore serves to eliminate one possible impurity source (the reference electrode) for the development of CdTe-based solar cells as well as to simplify the electrodeposition process and reduce cost at the same time. Again, the deposition temperature can be raised without the fear of exceeding the operating temperature limit of the reference electrode usually specified by the manufacturers $\left(\sim 70^{\circ} \mathrm{C}\right.$ for SCE and $\sim 100^{\circ} \mathrm{C}$ for $\mathrm{Ag} / \mathrm{AgCl}$ electrode). This will have the benefit of improving the crystallinity of the semiconductors deposited.

It is well known that CdTe can be grown to have ntype conductivity, i-type conductivity, or p-type conductivity simply by changing the stoichiometry of the material without involving external dopants $[13,14,16,17]$. A Cd-rich CdTe results in $\mathrm{n}$-CdTe, while a Te-rich CdTe results in $\mathrm{p}$-CdTe [17]. In electrodeposition, this stoichiometry change is easily achieved by varying the deposition potential. At slightly lower cathodic deposition potentials from the potential of perfect stoichiometry (PPS), within the possible deposition potential range of CdTe, $\mathrm{p}-\mathrm{CdTe}$ is obtained. At slightly higher cathodic deposition potentials from the PPS, n-CdTe is obtained [16], and, at the PPS, intrinsic stoichiometric CdTe (i-CdTe) is obtained. This simply shows that such a material can be deposited within a certain range of applied potential. This fact has also been observed using two-electrode system and recently published by the authors' group [18]. This same situation has also been reported for electrodeposited p-, i-, and ntype copper indium diselenide (CIS) with applied deposition potential window of $\sim 600 \mathrm{mV}$ in two-electrode system [8] and $\mathrm{p}^{+}-, \mathrm{p}-, \mathrm{i}-, \mathrm{n}-$, and $\mathrm{n}^{+}$-type copper indium gallium diselenide (CIGS), with applied deposition potential window of $\sim 950 \mathrm{mV}$ in three-electrode system [19]. In all these examples, it is therefore obvious that the electrodeposition of any particular semiconductor can actually take place over a certain range of applied potentials irrespective of the electrode system used. As another example, the work by Diso et al. [10] on two-electrode deposition of CdS layers shows that good quality CdS layers can be obtained within a deposition potential window of $\sim 200 \mathrm{mV}$ under the conditions they used. In the work by Takahashi et al. in [16] using three-electrode system, p-type and n-type CdTe were electrodeposited in applied cathodic deposition potentials from $300 \mathrm{mV}$ to $600 \mathrm{mV}$ versus $\mathrm{Ag} / \mathrm{AgCl}$, which is actually a potential window of $300 \mathrm{mV}$.

Quite recently, the authors' group has reported CdTebased solar cell efficiencies in the range $8-12 \%[12,20]$ while another group has reported high-efficiency CIGS solar cells [11], both using two-electrode systems. In any case, a comparative study of the use of both two-electrode and three-electrode configurations for the electrodeposition of semiconductor materials has never been reported. The present work therefore presents a comparative study of some properties of electrodeposited CdTe thin films grown using both two-electrode and three-electrode systems for thin film solar cell applications.

\section{Experimental Procedure}

Two similar deposition electrolytes were used in the electrodeposition of CdTe layers in both electrode configurations. Both electrolytes contain aqueous solutions of $1 \mathrm{M} \mathrm{CdSO}_{4}$ of $99.0 \%$ purity and $\sim 1 \mathrm{mM}$ of $99.999 \% \mathrm{TeO}_{2}$ dissolved in $\mathrm{H}_{2} \mathrm{SO}_{4}$ all in $800 \mathrm{~mL}$ of deionized water. In addition, the electrolytes contain $1 \mathrm{mM}$ each of $99.999 \% \mathrm{CdCl}_{2}$ and $\mathrm{CdF}_{2}$ as sources of $\mathrm{Cl}$ and $\mathrm{F}$ atoms for $\mathrm{n}$-type doping. All chemicals were obtained from Sigma Aldrich, United Kingdom. The use of the abovementioned dopants in this work follows from the fact that the halogens are well-known n-type dopants in CdTe, and they generally help to improve the efficiency of CdS/CdTe solar cells $[6,15,21]$. The two-electrode and three-electrode systems have high-purity carbon rod as the counter electrode (anode) and the three-electrode system has a saturated calomel electrode (SCE) as the reference electrode.

Before the addition of $\mathrm{TeO}_{2}$, cyclic voltammograms of $\mathrm{CdSO}_{4}$-only solutions were recorded for each electrode system using clean glass/fluorine-doped tin oxide (FTO) substrate as the working electrode (cathode) to determine the possible deposition potential of Cd. A computerized Gill AC potentiostat (ACM Instruments, Cumbria, UK) was used as the source of power. With this, electropurification of the $\mathrm{CdSO}_{4}$-only solutions was carried out at a temperature of $68.0 \pm 0.2^{\circ} \mathrm{C}$ for both electrode systems for 48 hours and at a cathodic potential slightly lower than the identified deposition potential of $\mathrm{Cd}$ as reported in a recent publication $[12,14]$. The aim of the electropurification process is to eliminate, from the solution, any possible detrimental metallic ions present in the $\mathrm{CdSO}_{4}$ that may be incorporated into $\mathrm{CdTe}$ during the main electrodeposition process due to the low purity of the $\mathrm{CdSO}_{4}$ chemical. This process was carried out using a clean glass/FTO substrate as the working electrode where the possible impurities are deposited from the electrolyte. As an advantage of electrodeposition in general continuous removal of impurities takes place as electrodeposition progresses in a process known as selfpurification. The temperature of $68.0 \pm 0.2^{\circ} \mathrm{C}$ was used to avoid damaging the reference electrode since its maximum operating temperature is $70.0^{\circ} \mathrm{C}$ according to the manufacturer's specifications. $\mathrm{TeO}_{2}$ solution was added after the electropurification process and the $\mathrm{pH}$ of both electrolytes adjusted to $2.00 \pm 0.02$. After stirring for 24 hours, another set of cyclic voltammograms was recorded to identify the possible range of deposition potentials for $\mathrm{CdTe}$. Five samples were then deposited on clean glass/FTO of dimensions $3.0 \mathrm{~cm}$ $\times 2.0 \mathrm{~cm} \times 3.0 \mathrm{~mm}$, from each electrolyte across the identified 


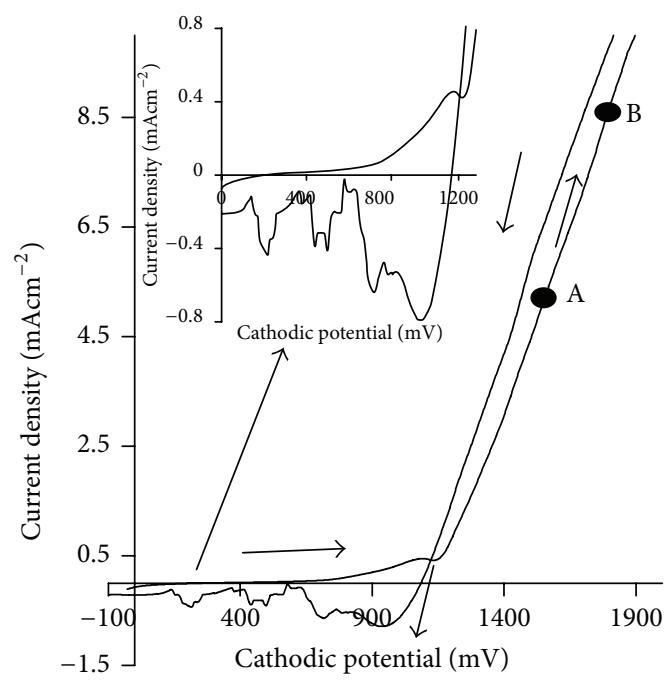

(a)

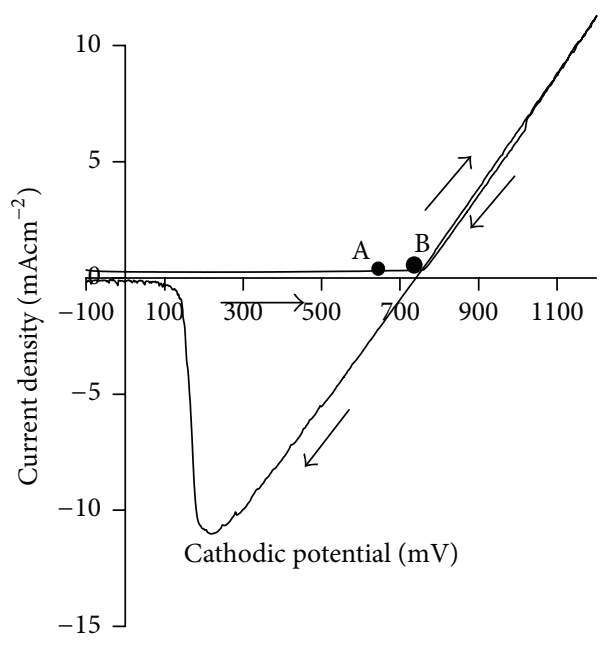

(b)

FIGURE 1: Cyclic voltammograms of CdTe deposition electrolytes for (a) two-electrode system and (b) three-electrode system.

deposition potential range. This size of glass/FTO is also the same used for the voltammograms for uniformity. The deposited CdTe materials were then characterised using Xray diffraction (XRD) measurements, photoelectrochemical (PEC) cell measurements, and optical absorption measurements. From the characterisation results, the best deposition potential for CdTe for each electrode system was identified. The best layers were deposited on glass/FTO substrates at cathodic potentials of $1578 \mathrm{mV}$ from the two-electrode system and $697 \mathrm{mV}$ versus SCE from the three-electrode system. Prior to annealing at $450^{\circ} \mathrm{C}$ for 15 minutes in air for solar cell fabrication, the glass/FTO/CdTe samples were dipped in a saturated aqueous solution of $\mathrm{CdCl}_{2}$ containing about $0.1 \mathrm{~g}$ of $\mathrm{CdF}_{2}$ and then dried in air.

$\mathrm{X}$-ray diffraction measurements were carried out using computerized Philips X'Pert Pro diffractometer (Philips Analytical, Almelo, Australia) with $\mathrm{Cu}-\mathrm{K} \alpha$ excitation wavelength of $1.5406 \AA$ in order to determine the crystal structure of the CdTe layers. PEC cell measurements were used to determine the electrical conductivity types of the CdTe layers deposited on glass/FTO. Optical absorption measurements were carried out using Cary 50 Scan UV-Vis spectrophotometer (Varian, Australia Pty Ltd.) to determine the absorption behaviour and the energy bandgaps of the layers. The results of the structural, electrical, and optical characterisations of the deposited CdTe layers are presented in the next section.

\section{Results and Discussion}

3.1. Cyclic Voltammetry. Figures 1(a) and 1(b) show the cyclic voltammograms of CdTe deposition electrolytes for (a) two-electrode system and (b) three-electrode system. When Figure 1(a) is zoomed in (see the inset), one can see that $\mathrm{Te}$ (with standard reduction potential $E^{0}=+0.593 \mathrm{~V}$ ) begins to deposit at a cathodic potential of $\sim 200 \mathrm{mV}$ in the forward sweep since it has a more positive standard reduction potential than $\mathrm{Cd}\left(E^{0}=-0.403 \mathrm{~V}\right)$. Deposition of $\mathrm{Cd}$ is observed to begin from $\sim 800 \mathrm{mV}$ as indicated by the noted increase of the current density. The deposition of Te-rich CdTe therefore starts from this point. Beyond this point, CdTe is obtained with higher deposition current density and increased $\mathrm{Cd}$ concentration. In the reverse sweep, the stripping off of $\mathrm{Cd}$ from the deposited layer is seen to begin at the point where the graph crosses to the negative current density axis. Peaks in the negative current indicate the removal of elemental $\mathrm{Cd}$ and $\mathrm{Cd}$ from the CdTe layer. Finally, Te is removed at the lower cathodic voltages.

Good quality n-CdTe layers were deposited from this two-electrode system in the cathodic potential range of $1576 \mathrm{mV}-1580 \mathrm{mV}$ (between points A and B) with the best layer appearing at a cathodic potential of $\sim 1578 \mathrm{mV}$ with a current density of $\sim 4.50 \mathrm{mAcm}^{-2}$ at a moderate stirring rate. This deposition potential was chosen based on the most intense XRD peaks from the (111) crystallographic plane and the sharpest optical absorption edge.

In Figure 1(b), deposition of Te from the three-electrode system begins as soon as a cathodic potential is applied across the working electrode in the forward sweep. This may be due to the presence of $\mathrm{CdCl}_{2}$ and $\mathrm{CdF}_{2}$ in the electrolytes. The deposition of $\mathrm{Cd}$ also follows without any clear indication of the potential from where this happens. However, a sharp rise in the CdTe deposition current density sets in at a cathodic potential of $\sim 750 \mathrm{mV}$. In the reverse scan, a large broad negative peak is observed. This broad peak represents the dissolution of elemental $\mathrm{Cd}$ and $\mathrm{Cd}$ from $\mathrm{CdTe}$ and the removal of Te from the cathode, in that order. From this system, good quality CdTe layers could be deposited in a cathodic potential ranging from $695 \mathrm{mV}$ to $699 \mathrm{mV}$ (between points A and B). However, just like in the case of the two-electrode system, the best cathodic deposition potential for this system was identified as $697 \mathrm{mV}$ versus SCE with a deposition current density of $\sim 0.30 \mathrm{mAcm}^{-2}$ under 


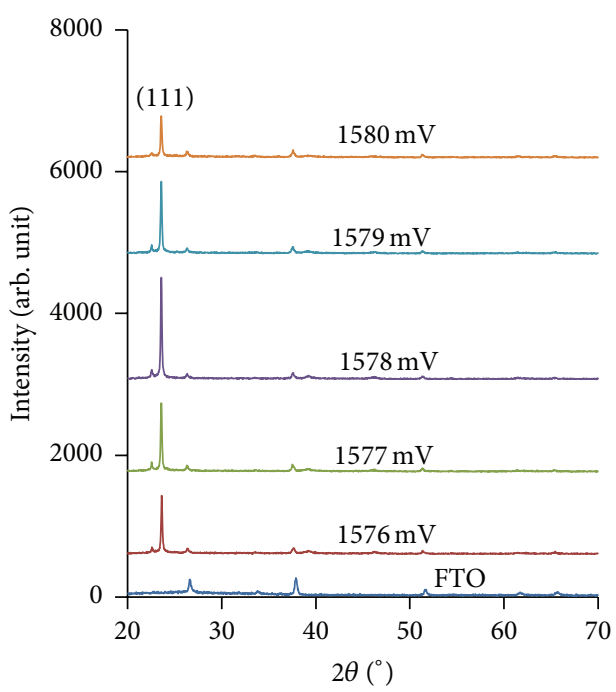

(a) Two-electrode

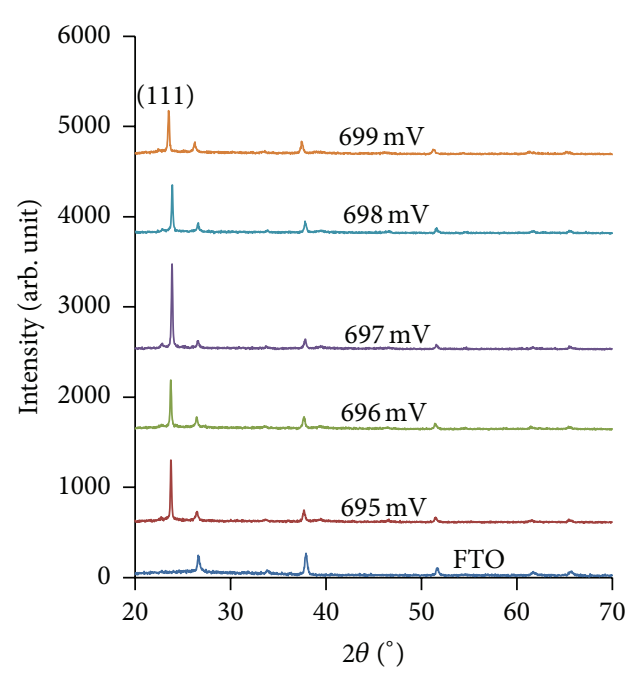

(b) Three-electrode

FIGURE 2: XRD patterns of as-deposited CdTe layers grown at five different cathodic voltages for 1 hour using (a) two-electrode system and (b) three-electrode system.

moderate stirring. The observed lower deposition current density in the three-electrode system may be a result of poorly cleaned glass/FTO used for the voltammogram and does not in any way suggest poor performance of the three-electrode system. However, this current density is very much above the range of what we have always identified as optimum deposition current density $0.15-0.18 \mathrm{mAcm}^{-2}$ for CdTe for both electrode systems from experience. The deposition current densities in both cases were reduced to the range $0.15-0.18 \mathrm{mAcm}^{-2}$ during the CdTe deposition by reducing the stirring rate as is common in electrodeposition. In this current density range, the deposition is gradual and more uniform deposits are usually obtained. It is worthy of note that the amount of Te ions in the electrolyte also affects the deposition current density. High Te ion content results in high current density and of course Te-rich CdTe since Te will always deposit first and easily crystallises on the substrate.

3.2. X-Ray Diffraction (XRD) Study. Figures 2(a) and 2(b) show XRD patterns of the two sets of as-deposited CdTe samples grown using two-electrode and three-electrode system, respectively. These samples in each case were grown for 1 hour at five different cathodic potentials within the identified deposition voltage range. Voltages were varied in steps of $1 \mathrm{mV}$ in each case. The thicknesses of the samples are assumed to be comparable without much disparity since the surface areas of the glass/FTO substrates are the same and the average deposition current densities for the two systems do not differ by so much (in the range of $0.15-0.18 \mathrm{mAcm}^{-2}$ ) and the deposition time is the same. In electrodeposition, the thickness, $T$, of the deposited film for any given electrolyte, is theoretically estimated using Faraday's equation $(T=M J t / n F \rho)$ in which the deposition current density, $J$ (which takes into account the surface area of the film), and the deposition time, $t$, are the major variables. $M$ is the molecular weight of the material deposited, $n$ is the number of electrons transferred in the process, $\rho$ is the density of the material deposited, and $F$ is Faraday's constant. Both Figures 2(a) and 2(b) show the presence of the strong preferential orientation of the prominent peak corresponding to (111) crystallographic plane of cubic CdTe material. The other visible peaks present belong to the underlying FTO substrate. In fact, based on the peak intensities of (111) preferential orientation, the best cathodic growth voltages can be seen clearly from both figures. For the two-electrode system, this corresponds to $1578 \mathrm{mV}$, while for the three-electrode system it corresponds to $697 \mathrm{mV}$. From these figures also one notes that the as-deposited CdTe grown using these different electrode configurations are similar in structural quality showing the same preferential orientation of the crystallites in (111) crystal plane.

Figures 3(a) and 3(b) show the XRD patterns of the annealed samples of Figure 2. Again (111) preferential orientation is very prominent for both electrode systems at all deposition voltages.

There is also a gradual emergence of two other peaks corresponding to reflections from (220) and (311) crystal planes of the same cubic CdTe. These two peaks are more visible in Figure 3(a) than in Figure 3(b). This slight difference may be due to difference in the effective deposition rate as a result of slight difference in deposition current densities in the two different deposition electrolytes. In fact it was generally observed in the course of this work that the two-electrode system always showed higher deposition current density compared to the three-electrode system. The overall average deposition current density maintained for the deposition of all the samples in the two-electrode system at moderate stirring rate of 400 rotations per minute was $\sim 0.18 \mathrm{mAcm}^{-2}$ while that for the three-electrode system was $\sim 0.15 \mathrm{mAcm}^{-2}$. High deposition current densities usually result in very quick 


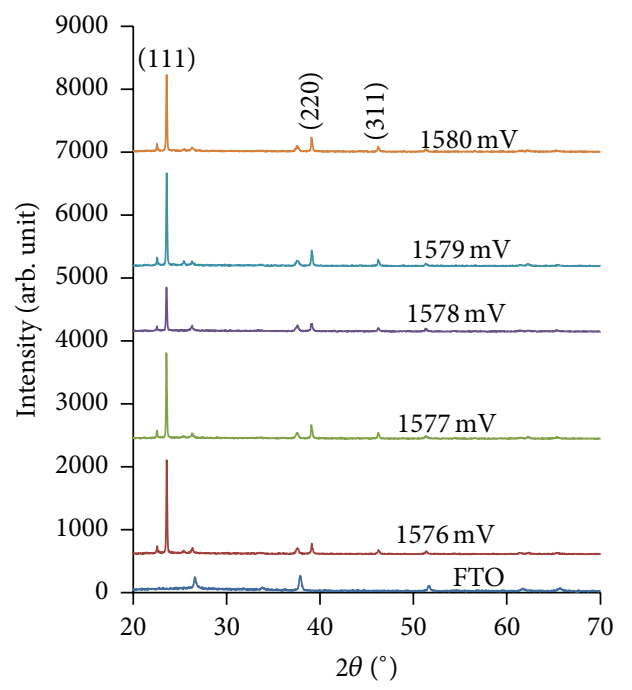

(a) Two-electrode

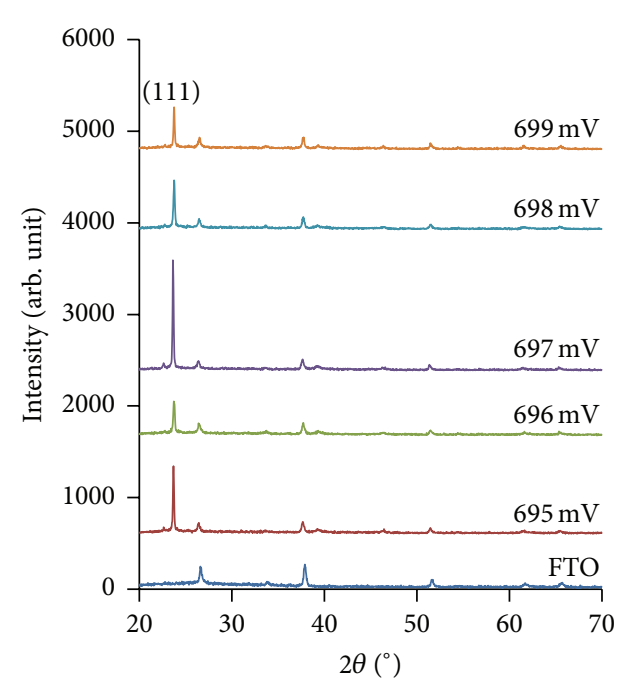

(b) Three-electrode

FIGURE 3: XRD patterns of CdTe layers grown at different cathodic voltages for 1 hour using (a) two-electrode system and (b) three-electrode system and annealed at $450^{\circ} \mathrm{C}$ for 15 minutes.

depositions with tellurium-richness as seen from the very shiny layers obtained. Again, the postdeposition annealing in $\mathrm{CdCl}_{2}+\mathrm{CdF}_{2}$ environment could result in the appearance of these additional (220) and (311) XRD peaks since they are not observed in the as-deposited samples. It is possible that there may have been present, in the deposited CdTe, some unreacted $\mathrm{Te}$ as well as $\mathrm{Cd}$ which eventually reacted in the annealing process in the presence of both heat (at $450^{\circ} \mathrm{C}$ ) and $\mathrm{CdCl}_{2}+\mathrm{CdF}_{2}$ mixture to give rise to better crystalline and stoichiometric CdTe materials, in a process of recrystallisation, which resulted in the appearance of the additional XRD peaks. This situation could have been more pronounced in the two-electrode system.

In the two-electrode system (Figure 3(a)), there appears to be a shift in the best deposition voltage in terms of the intensity of the (111) peak. The best voltage in this case appears to be $1576 \mathrm{mV}$. This shift from the original values of $1578 \mathrm{mV}$ must have to do with recrystallisation which also resulted in the appearance of the (220) and (311) peaks as already mentioned. In the case of the three-electrode system, the best growth voltage remains $697 \mathrm{mV}$ based on the highest (111) XRD peak intensity. The samples in Figure 3 were annealed at $450^{\circ} \mathrm{C}$ for 15 minutes after $\mathrm{CdCl}_{2}+\mathrm{CdF}_{2}$ treatment. The XRD data of CdTe materials from both electrode configurations match the Joint Committee on Powder Diffraction and Standards (JCPDS) reference file number 00-015-0770. The crystallite sizes estimated using the Scherer equation for (111) peaks of CdTe materials from both electrode systems are comparable with values in the ranges of $18.7-49.8 \mathrm{~nm}$ for asdeposited materials and $18.7-77.0 \mathrm{~nm}$ for annealed materials.

3.3. Photoelectrochemical (PEC) Cell Study. Table 1 shows the PEC cell signal results of as-deposited CdTe layers grown using two-electrode system and three-electrode system. The results show that the as-deposited CdTe layers were n-type in electrical conduction irrespective of the electrode configuration used and the PEC signal values of samples from both electrode configurations are comparable.

PEC cell measurement is a quick way of determining the conductivity types of semiconductors especially when they are deposited on conducting substrates like glass/FTO as used in this work. In this situation, standard methods such as Hall Effect measurement could not be used, due to the presence of the underlying conducting substrate upon which the CdTe layers are grown. This is because, in the Hall Effect measurement, current would naturally prefer to flow through the conductive path of least resistance (i.e., through the conducting substrate) instead of flowing through the CdTe semiconductor under investigation thereby producing misleading results. For this reason, PEC measurement becomes the only alternative for the determination of the electrical conductivity types of these semiconductors grown on conducting substrates as it is extremely difficult in most cases to detach the layers from the FTO substrates.

The PEC cell technique is based on the formation of a solid (semiconductor)/liquid (electrolyte) junction when a semiconductor is brought into intimate contact with a suitable electrolyte. A Schottky-type potential barrier is formed at the semiconductor/electrolyte interface and the direction of band-bending in the semiconductor depends on the electrical conductivity type of the semiconductor. The voltage across the FTO and a counter electrode (carbon in our case) is recorded under dark condition using a voltmeter. The system is then illuminated using white light and voltage across the two terminals is recorded again. The difference between the voltage under illumination $\left(V_{L}\right)$ and that under dark condition $\left(V_{D}\right)$ gives the PEC signal. The sign of the PEC signal is then used to determine the conductivity type of the semiconductor involved. ntype and p-type semiconductors have opposite PEC signals for the same electrolyte. If an n-type semiconductor has 
TABLE 1: PEC signal results of as-deposited CdTe layers grown using the two-electrode system and three-electrode system.

\begin{tabular}{|c|c|c|c|c|c|c|c|c|c|}
\hline \multicolumn{5}{|c|}{ Two-electrode (As-deposited) } & \multicolumn{5}{|c|}{ Three-electrode (As-deposited) } \\
\hline$V_{g}(\mathrm{mV})$ & $V_{D}(\mathrm{mV})$ & $V_{L}(\mathrm{mV})$ & $\operatorname{PEC}\left(V_{L}-V_{D}\right)(\mathrm{mV})$ & Type & $V_{g}(\mathrm{mV})$ & $V_{D}(\mathrm{mV})$ & $V_{L}(\mathrm{mV})$ & $\operatorname{PEC}\left(V_{L}-V_{D}\right)(\mathrm{mV})$ & Type \\
\hline 1576 & -192 & -264 & -72 & $\mathrm{n}$ & 695 & -208 & -269 & -62 & $\mathrm{n}$ \\
\hline 1577 & -168 & -222 & -54 & $\mathrm{n}$ & 696 & -219 & -292 & -73 & $\mathrm{n}$ \\
\hline 1578 & -195 & -251 & -56 & $\mathrm{n}$ & 697 & -195 & -256 & -61 & $\mathrm{n}$ \\
\hline 1579 & -159 & -249 & -90 & $\mathrm{n}$ & 698 & -200 & -278 & -78 & $\mathrm{n}$ \\
\hline 1580 & -190 & -261 & -71 & $\mathrm{n}$ & 699 & -255 & -305 & -50 & $\mathrm{n}$ \\
\hline
\end{tabular}

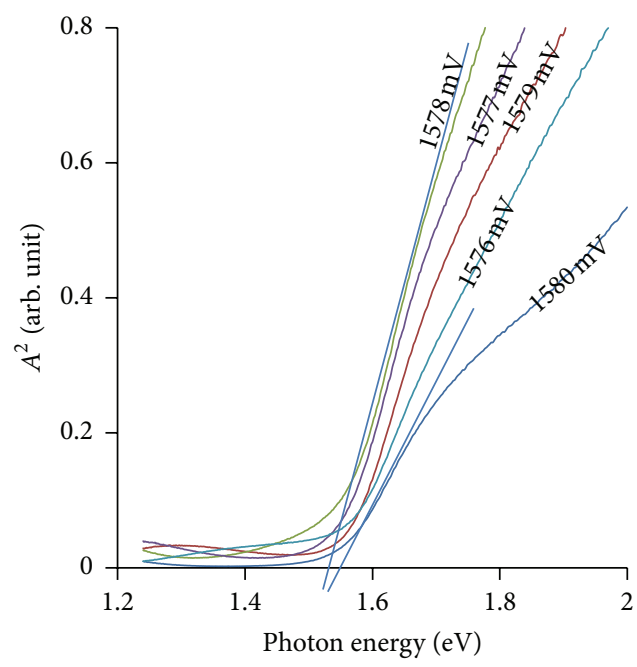

(a) Two-electrode

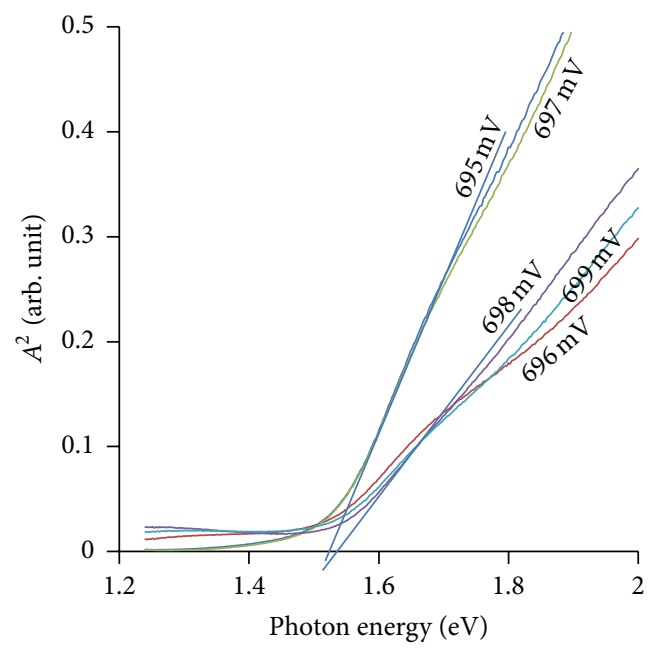

(b) Three-electrode

FIGURE 4: Square of absorbance $\left(A^{2}\right)$ versus photon energy for as-deposited CdTe samples grown with (a) two-electrode system and (b) three-electrode system for 1 hour at different cathodic voltages.

a negative PEC signal for any given electrolyte, then a ptype semiconductor will have a positive PEC signal for the same electrolyte. This is because these two semiconductors have band-bending in opposite directions when in contact with the electrolyte. The magnitude of the PEC signal gives an indication of the level of doping concentration in the semiconductor. Large PEC signals indicate moderate doping and hence formation of healthy depletion region. A heavily doped semiconductor will have a low PEC signal due to the formation of a thin depletion region. If a metal or an insulator is used in place of the semiconductor, zero PEC signal will be registered in both cases as there is no bandbending associated with these types of materials. The PEC measurements reported in this work were carried out using aqueous solution of $0.1 \mathrm{M} \mathrm{Na}_{2} \mathrm{~S}_{2} \mathrm{O}_{3}$ as an electrolyte and a digital voltmeter.

3.4. Spectrophotometry. Figures 4(a) and 4(b) show the optical absorption spectra of as-deposited CdTe layers using the two-electrode system and three-electrode system, respectively. The absorption edges of the as-deposited samples for both electrode configurations are not sharp. This is as a result of poor crystalline quality and probably poor stoichiometry of the as-deposited CdTe materials especially since they were grown at relatively low temperature as mentioned earlier.
However, the absorption edges of the three-electrodegrown samples are slightly weaker than those of twoelectrode system perhaps due to the reasons given earlier for the XRD result. The energy bandgaps obtained for all the materials are however similar for both electrode configurations, giving values in the range $1.53-1.55 \mathrm{eV}$, which is above the bulk value of $1.45 \mathrm{eV}$ for $\mathrm{CdTe}$ for the same reason of poor crystallinity and stoichiometry given above.

Figures 5(a) and 5(b) also show the optical absorption of the same CdTe samples of Figure 4 after annealing at $450^{\circ} \mathrm{C}$ for 15 minutes. Clearly, there is significant improvement in the absorption edges of the samples after annealing. This is certainly due to the improvement in both crystallinity and stoichiometry of these materials as a result of the postdeposition heat treatment in the presence of $\mathrm{CdCl}_{2}+\mathrm{CdF}_{2}$.

The improvement in crystalline quality after annealing is also evident from the XRD results presented earlier. The overall improvement in quality by the annealing process is also seen in the improved absorption edges of all the $\mathrm{CdTe}$ materials. The energy bandgaps of the annealed CdTe materials from both electrode configurations are narrower than those of as-deposited samples and fall in the range 1.45$1.48 \mathrm{eV}$. These bandgap values are also closer to the bulk value, showing that the quality of the materials has improved considerably after annealing. 


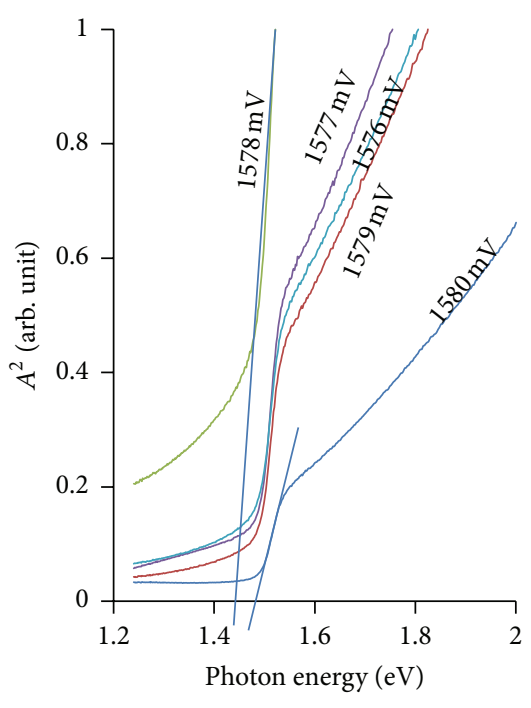

(a) Two-electrode

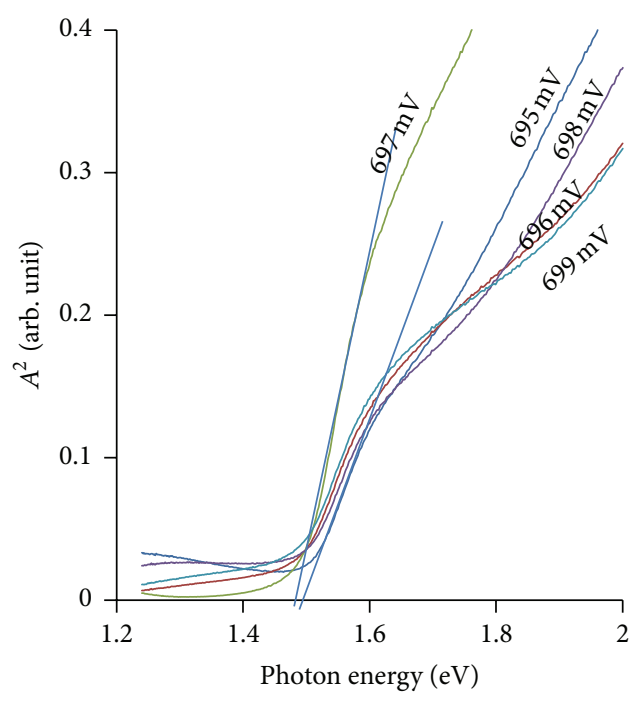

(b) Three-electrode

FIGURE 5: Square of absorbance $\left(A^{2}\right)$ versus photon energy of annealed CdTe samples grown with (a) two-electrode system and (b) threeelectrode system at different cathodic voltages for 1 hour.

\section{Conclusion}

A comparative study of the electrodeposition and characterisation of CdTe thin films on glass/FTO substrates using both two-electrode configuration and three-electrode configuration has been presented. X-ray diffraction, photoelectrochemical cell measurements, and optical absorption spectrophotometry results show that the electrodeposited CdTe layers from both electrode configurations possess similar and comparable structural, optical, and electronic properties. The results further highlight the possible advantages of the use of the two-electrode configuration in the electrodeposition of semiconductor materials for possible device fabrication without compromising the essential device qualities of these materials. Elimination of a possible impurity source (the reference electrode), process simplification, ability to grow better materials at high temperatures, and cost reduction are some of these advantages achievable through the use of the two-electrode configuration over three-electrode configuration.

\section{Competing Interests}

The authors declare that there are no competing interests regarding the publication of this paper.

\section{Acknowledgments}

Thanks are due to Pilkington Group Ltd., UK, for providing glass/FTO substrates for this work. O. K. Echendu is thankful to the Tertiary Education Trust Fund, Nigeria, and the Federal University of Technology, Owerri, Nigeria, for financial support.

\section{References}

[1] M. P. R. Panicker, M. Knaster, and F. A. Kroger, "Cathodic deposition of cdte from aqueous electrolytes," Journal of the Electrochemical Society, vol. 125, no. 4, pp. 566-572, 1978.

[2] B. M. Basol, "High-efficiency electroplated heterojunction solar cell," Journal of Applied Physics, vol. 55, no. 2, pp. 601-603, 1984.

[3] B. M. Basol, "Electrodeposited CdTe and HgCdTe solar cells," Solar Cells, vol. 23, no. 1-2, pp. 69-88, 1988.

[4] D. Cunningham, M. Rubcich, and D. Skinner, "Cadmium telluride PV module manufacturing at BP solar," Progress in Photovoltaics: Research and Applications, vol. 10, no. 2, pp. 159$168,2002$.

[5] N. W. Duffy, L. M. Peter, and R. L. Wang, "Characterisation of CdS-CdTe heterojunctions by photocurrent spectroscopy and electrolyte electroreflectance/absorbance spectroscopy (EEA/EER)," Journal of Electroanalytical Chemistry, vol. 532, no. 1-2, pp. 207-214, 2002.

[6] S. Dennison, "Dopant and impurity effects in electrodeposited CdS/CdTe thin films for photovoltaic applications," Journal of Materials Chemistry, vol. 4, no. 1, pp. 41-46, 1994.

[7] F. A. Kroger, "Cathodic deposition and characterization of metallic or semiconducting binary alloys or compounds," Journal of The Electrochemical Society, vol. 125, no. 12, pp. 20282034, 1978.

[8] I. M. Dharmadasa, R. P. Burton, and M. Simmonds, "Electrodeposition of $\mathrm{CuInSe} \mathrm{S}_{2}$ layers using a two-electrode system for applications in multi-layer graded bandgap solar cells," Solar Energy Materials and Solar Cells, vol. 90, no. 15, pp. 2191-2200, 2006.

[9] A. Bouraiou, M. S. Aida, E. Tomasella, and N. Attaf, "ITO substrate resistivity effect on the properties of $\mathrm{CuInSe}_{2}$ deposited using two-electrode system," Journal of Materials Science, vol. 44, no. 5, pp. 1241-1244, 2009.

[10] D. G. Diso, G. E. A. Muftah, V. Patel, and I. M. Dharmadasa, "Growth of CdS layers to develop all-electrodeposited 
CdS/CdTe thin-film solar cells," Journal of the Electrochemical Society, vol. 157, no. 6, pp. H647-H651, 2010.

[11] R. N. Bhattacharya, "CIGS-based solar cells prepared from electrodeposited stacked Cu/In/Ga layers," Solar Energy Materials and Solar Cells, vol. 113, pp. 96-99, 2013.

[12] O. K. Echendu, F. Fauzi, A. R. Weerasinghe, and I. M. Dharmadasa, "High short-circuit current density CdTe solar cells using all-electrodeposited semiconductors," Thin Solid Films, vol. 556, pp. 529-534, 2014.

[13] D. G. Diso, Research and development of CdTe-based thin film solar cells [Ph.D. thesis], Sheffield Hallam University, Sheffield, UK, 2011, http://shura.shu.ac.uk/id/eprint/4941.

[14] I. M. Dharmadasa, P. A. Bingham, O. K. Echendu et al., "Fabrication of CdS/CdTe-based thin film solar cells using an electrochemical technique," Coatings, vol. 4, no. 3, pp. 380-415, 2014.

[15] K. Zanio, Semiconductors and Semimetals, vol. 13 'Cadmium Telluride’, vol. 13, Academic Press, New York, NY, USA, 1978.

[16] M. Takahashi, K. Uosaki, H. Kita, and S. Yamaguchi, "Resistivity, carrier concentration, and carrier mobility of electrochemically deposited CdTe films," Journal of Applied Physics, vol. 60, no. 6, pp. 2046-2049, 1986.

[17] V. B. Patil, D. S. Sutrave, G. S. Shahane, and L. P. Deshmukh, "Cadmium telluride thin films: growth from solution and characteristics," Thin Solid Films, vol. 401, no. 1-2, pp. 35-38, 2001.

[18] D. G. Diso, F. Fauzi, O. K. Echendu, O. I. Olusola, and I. M. Dharmadasa, "Optimisation of CdTe electrodeposition voltage for development of CdS/CdTe solar cells," Journal of Materials Science: Materials in Electronics, 2016.

[19] I. M. Dharmadasa, N. B. Chaure, G. J. Tolan, and A. P. Samantilleke, "Development of $\mathrm{p}^{+}, \mathrm{p}, \mathrm{i}, \mathrm{n}$, and $\mathrm{n}^{+}$-type CuInGa $\mathrm{Se}_{2}$ layers for applications in graded bandgap multilayer thinfilm solar cells," Journal of the Electrochemical Society, vol. 154, no. 6, pp. H466-H471, 2007.

[20] O. Echendu and I. Dharmadasa, "Graded-bandgap solar cells using all-electrodeposited ZnS, CdS and CdTe thin-films," Energies, vol. 8, no. 5, pp. 4416-4435, 2015.

[21] S. Mazzamuto, L. Vaillant, A. Bosio, N. Romeo, N. Armani, and G. Salviati, "A study of the CdTe treatment with a Freon gas such as $\mathrm{CHF}_{2} \mathrm{Cl}$," Thin Solid Films, vol. 516, no. 20, pp. 7079-7083, 2008. 

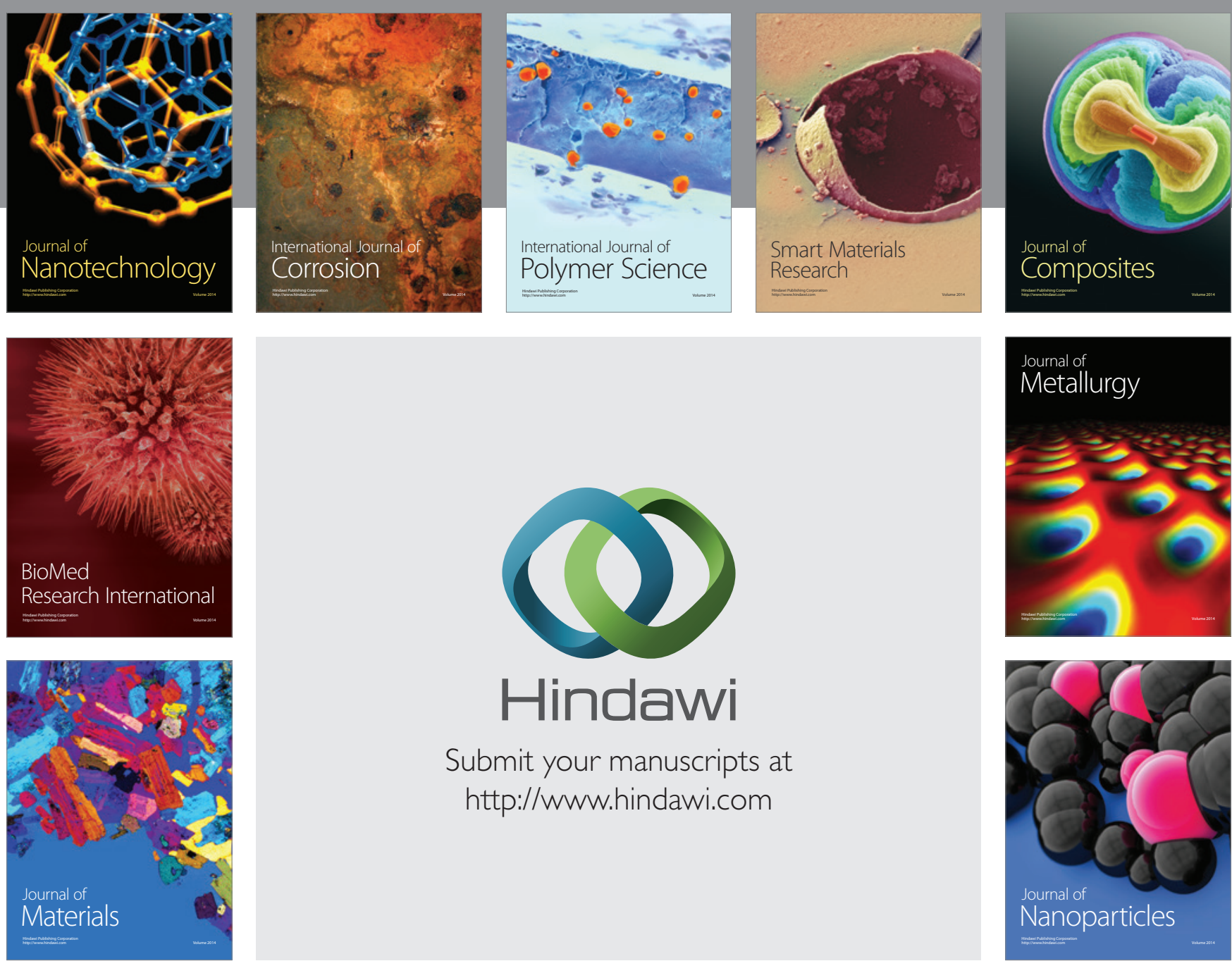

\section{Hindawi}

Submit your manuscripts at

http://www.hindawi.com

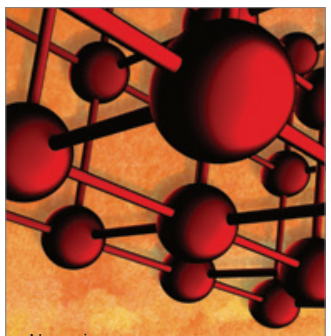

Materials Science and Engineering
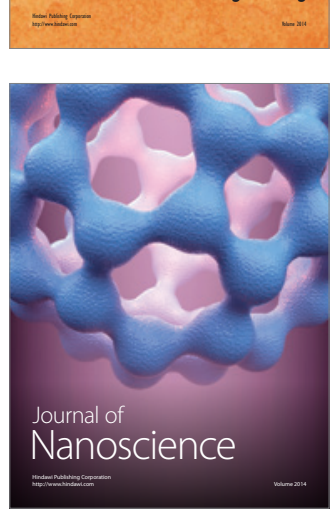
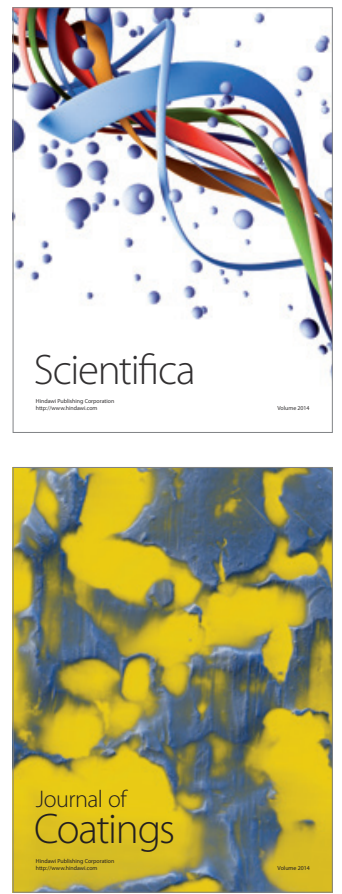
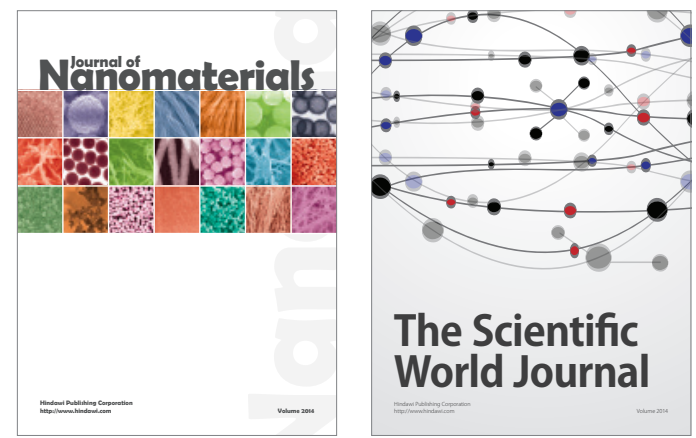

The Scientific World Journal
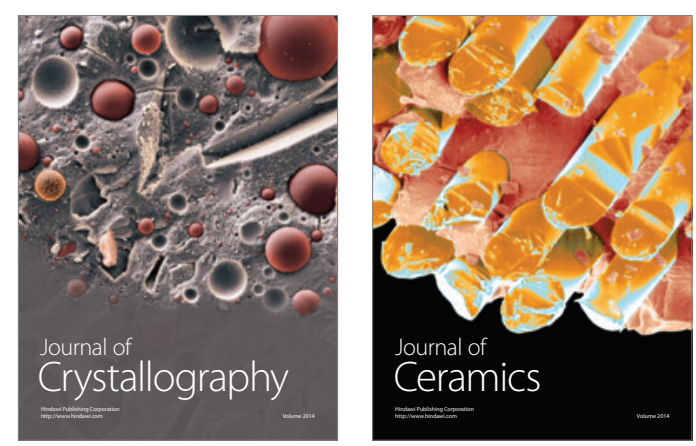
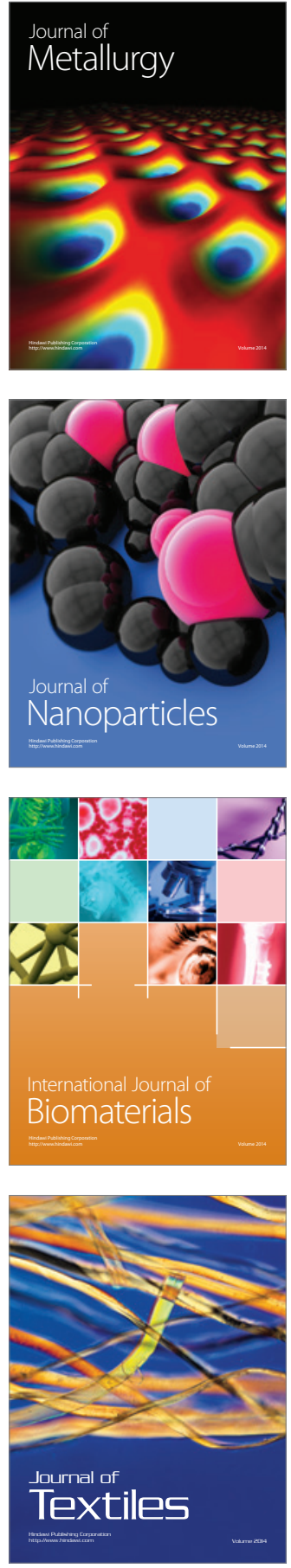